Lepr Rev (1989) 60, 28-32

\title{
The role of nerve biopsies in the diagnosis and management of leprosy
}

\author{
R NILSEN,$* \dagger$ G MENGISTU $\dagger \&$ B B REDDY $\ddagger$ \\ *Institute of International Health, University of Bergen, Norway; \\ $\dagger$ Armauer Hansen Research Institute, AHRI; $\ddagger$ All African Leprosy \\ \& Rehabilitation Training Centre, ALERT, Addis Ababa, Ethiopia.
}

\section{Accepted for publication 21 October 1988}

\begin{abstract}
Summary Skin and nerve biopsies from 81 patients clinically suspected to have leprosy were studied. Histologically $54 \%$ of the patients showed leprosy. Both nerve and skin biopsies were histologically diagnostic of leprosy in $64 \%$ of these cases while $32 \%$ were diagnostic in the nerve but not skin biopsy. In the 11 patients with multibacillary leprosy $(\mathrm{BI} \geq 2)$ a multibacillary picture was seen in all nerve biopsies while 8 patients exhibited a paucibacillary leprosy of the skin and a multibacillary leprosy in the nerve. The present results emphasize that leprosy is a disease of peripheral nerves and that diagnostic criteria other than skin parameters is important to reach a proper diagnosis. The evident possibility of having patients with a multibacillary leprosy in peripheral nerves and paucibacillary in skin emphasize the need of clinical studies to clarify the criteria for the diagnosis of paucibacillary leprosy and the drug regimen for this group of patients.
\end{abstract}

\section{Introduction}

Leprosy of peripheral nerves is the most common cause of peripheral neuropathy world wide. ${ }^{5}$ Although lesions in nerves and other tissues have been known since the earliest writings on this disease, it is the external, visible cutaneous lesions which have held the interest of the leprologists. ${ }^{6}$ Histological examinations for diagnostic purposes have mainly been performed on skin. The nerve damages, however, may start bef ore, during or after leprosy treatment and are often associated with reactional episodes, namely reversal reaction and erythema nodosum leprosy. ${ }^{4,10}$ Clinical assessment of the nerves to identify the normal variations as well as the pathology of the nerves requires a lot of practical experience and may not yet be sufficient to document the status of nerve involvement. ${ }^{7}$ Although the main criteria for diagnosis of leprosy are related to skin parameters, leprosy is primarily a disease of peripheral nerves. ${ }^{9}$ Three studies have shown discrepancies in histopathological findings including the bacterial load between different tissues in leprosy patients. ${ }^{3,12,13}$ Antia \& Pandya have found a higher load of bacteria in biopsies from the peripheral nerves than from skin and lymph nodes. ${ }^{3}$

This study was undertaken to compare the histopathological results of the nerve biopsies with a classification based on a parallel skin biopsy. Emphasis was put on the role of nerve biopsies in detection of patients with multibacillary leprosy. 


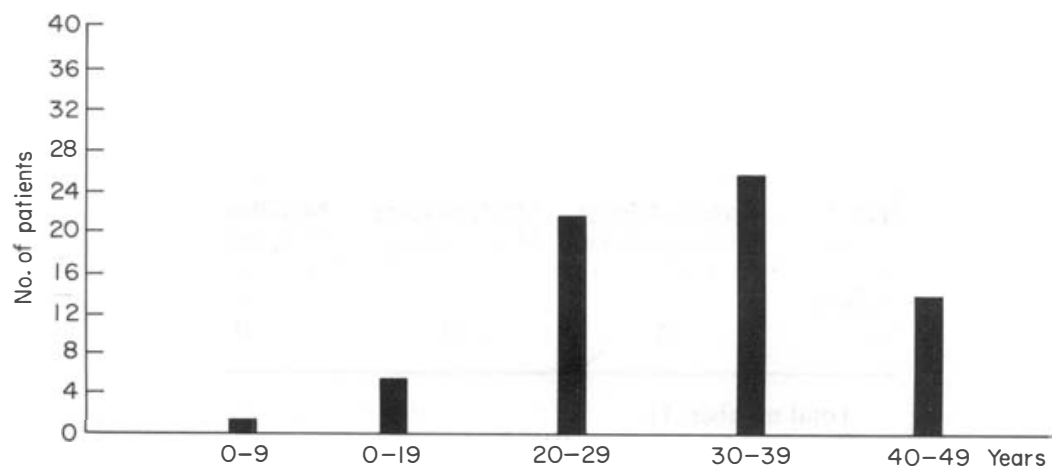

No. of patients: $53(65 \%)$ males; $28(35 \%)$ females.

Figure 1. Age and sex distribution of patients for nerve biopsies.

\section{Material and methods}

In 1985, 237 leprosy patients were referred for nerve biopsies at All African Leprosy and Training Rehabilitation Centre, ALERT, Addis Ababa, Ethiopia. In 81 of these cases a parallel skin and nerve biopsy was obtained. The age and sex distribution are shown in Figure 1.

Nerve biopsies were mainly taken from the radial cutaneous nerve $(n=66)$, but also from the sural $(n=11)$, peroneal $(n=3)$ and ulnar $(n=1)$ nerves. Biopsies were made under local anaesthesia. Skin punch biopsies were taken from the skin lesions and not from skin overlying the nerve biopsy site. Nerve biopsies were taken from the same areas in all patients. Parts of the biopsies were taken from clinically thickened nerves, while the rest were taken from clinically normal nerves. The specimens were immediately fixed in $4 \%$ buffered formaldehyde or FMA fixative, dehydrated and embedded in paraffin by routine methods. ${ }^{11}$ Sections, $4-\mu \mathrm{m}$ thick, were cut, processed and stained with a modified Fite stain and the TRIFF stain both suitable for the demonstration of acid-fast bacilli. ${ }^{11}$

Skin biopsies were classified histopathologically according to the Ridley-Jopling and Ackerman classifications for dermatitis. ${ }^{1,9,11}$ In addition, the respective bacterial index (BI) was recorded. Nerve biopsies with a $\mathrm{BI} \geq 2$ were classified as multibacillary (MB), biopsies with a $\mathrm{BI} \leq 1$ as paucibacillary (PB) leprosy.

The tentative clinical diagnosis obtained was extracted from the biopsy request form and the clinical cards at the hospital.

Table 1 Diagnosis of leprosy in parallel skin and nerve biopsies

\begin{tabular}{lccc}
\hline \multicolumn{4}{c}{ Combinations of skin and nerve histology } \\
\hline $\begin{array}{l}\text { Skin } \\
\text { Nerve }\end{array}$ & + & - & - \\
\hline $\begin{array}{l}\text { Number } \\
\%\end{array}$ & + & + & - \\
\hline
\end{tabular}

Total number: 44 .

+ , histologically diagnostic for leprosy.

- , not histologically diagnostic for leprosy. 
Table 2 Multibacillary leprosy: comparison of skin and nerve biopsies

\begin{tabular}{|c|c|c|c|}
\hline \multicolumn{4}{|c|}{ Combinations of nerve and skin } \\
\hline Skin & Paucibacillary & Multibacillary & Multibacillary \\
\hline Nerve & Multibacillary & Multibacillary & Paucibacillary \\
\hline Number & 8 & 3 & 0 \\
\hline$\%$ & 73 & 27 & 0 \\
\hline
\end{tabular}

Total number: 11 .

Paucibacillary means a $\mathrm{BI} \leq 2$.

Multibacillary means a $\mathrm{BI} \geq 2$.

\section{Results}

In $44(55 \%)$ of the 81 patients studied a histological diagnosis of leprosy was given (Table 1). Twenty-eight $(64 \%)$ of these patients demonstrated skin and nerve biopsies diagnostic of leprosy, while 14 of the 44 patients ( $32 \%$ ) had histologically diagnostic leprosy in the peripheral nerve biopsy without corresponding positive skin biopsy (Table 1). In 2 patients a diagnostic skin biopsy and a non-diagnostic nerve biopsy were found.

In $11(25 \%)$ of the patients with histologically diagnostic leprosy of multibacillary leprosy $(\mathrm{BI} \geq 2)$ was found in either nerve or skin (Table 2). Eight $(73 \%)$ of these 11 multibacillary patients revealed multibacillary leprosy in the nerve biopsy and paucibacillary leprosy in the skin biopsy while 3 showed multibacillary leprosy in both skin and nerve biopsies.

In $37(45 \%)$ of the 81 patients there were no histological diagnostic findings of leprosy in the nerve or the skin biopsies. In $18(32 \%)$ of these patients (Table 3 ) normal histology of both the skin and the nerve biopsies were found. However, of these 18 patients, 7 had been given a clinical diagnosis of probable leprosy while 11 had received a diagnosis of leprosy.

In $5(9 \%)$ of the patients without diagnostic leprosy a fibrotic nerve lesion and a normal skin were found. Although the fibrosis might well be a consequence of leprosy no diagnostic indications of leprosy were found in these lesions. Five $(9 \%)$ of the patients showed chronic inflammation in the nerve biopsies, but without any other histological or bacteriological criteria for leprosy.

Table 3 Histology of skin and nerve biopsies from patients not diagnostic of leprosy

\begin{tabular}{|c|c|c|c|c|c|}
\hline \multicolumn{6}{|c|}{ Combinations of skin and nerve histology } \\
\hline Skin & Norm* & $\mathrm{CI} \dagger$ & Norm & Norm & $\mathrm{CI}$ \\
\hline Nerve & Norm & Norm & Fibr $\ddagger$ & CI & CI \\
\hline Number & 18 & 9 & 5 & 2 & 3 \\
\hline$\%$ & $31 \cdot 5$ & $15 \cdot 7$ & $8 \cdot 8$ & $3 \cdot 5$ & $5 \cdot 2$ \\
\hline
\end{tabular}

Total number: 37 .

* Norm, normal findings histologically.

$\dagger \mathrm{CI}$, chronic inflammation.

$\ddagger$ Fibr., fibrosis and hyalinization histologically. 


\section{Discussion}

The present study showed that there was a marked discrepancy in the histological and bacteriological picture between nerve and skin lesions of a significant group of the leprosy patients studied. The exact magnitude of this difference in the whole leprosy group is difficult to anticipate from the present study due to the fact that the biopsies were taken from a rather unselected group of patients. Many of the patients were referred for biopsies due to uncertain clinical diagnosis and doubtful skin symptoms.

The data obtained from the group of patients with a histological diagnosis of leprosy present three main patterns (Table 1). One third (32\%) of the patients exhibited a diagnostic nerve biopsy and a non-diagnostic skin biopsy. These results from Ethiopia correspond to findings from India where 19 of the 36 leprosy patients had a higher bacillary load and a more lepromatous picture in nerves than in skin. ${ }^{13}$ The reliability of using nerve biopsies to disclose the status of the disease also corresponds with the findings of Antia et al. who have found nerve involvement prior to any clinical manifestations. ${ }^{2,3}$ Our results are in contradiction to those of a study from the People's Republic of China where they have found the same histological findings in skin and nerve lesions from 92 autopsies. ${ }^{14}$ They had, however, a comment that bacilli were more easily found in TT nerves than TT skin. In spite of a high number of bacteria being found in nerve than skin lesions, Ridley \& Ridley have suggested from morphological studies of patients from Nepal that skin lesions represented the general tissue response of the patients. ${ }^{12}$ In the present study, 8 of the 44 patients with diagnostic leprosy demonstrated a multibacillary leprosy in the nerve while the parallel skin biopsy showed paucibacillary leprosy. Immunological studies of both nerve and skin biopsies in these patients revealed that nerve lesions may have an immunological picture of a non-responsive leprosy in contrast to skin lesions. ${ }^{8}$ This can explain the results from studies in India where one study ${ }^{13}$ shows that 7 of the 8 patients with relapses displayed relapses only in the nerve. An immunologically non-responsive form of leprosy can thus reside in nerve lesions and a responsive form in skin lesions. These results, however, are in contrast to the conclusions made by Ridley \& Ridley claiming that the skin tissue response demonstrates the general tissue response towards Mycobacterium leprae..$^{12}$

This discrepancy in both the bacteriological and immunological status of the nerves compared to the skin should be considered when establishing treatment programmes for leprosy. The patients studied were given a treatment according to the WHO's regimen of multidrug therapy (MDT) for leprosy. With only a skin smear or a skin biopsy these patients would have been treated as paucibacillary cases with possible relapse as a consequence.

The criteria used for classification at present are mainly based on the status of skin lesions and thus not reflecting the nerve lesions. From the present results it might therefore be reasonable to question if the same drug regimen should be used for patients with paucibacillary as for multibacillary leprosy. To evaluate the treatment regimen, however, a well organized and randomized trial should be conducted.

Although nerve biopsies have been proven to be important, the need for a good histology laboratory and a pathologist makes this not applicable for the leprosy problems of the developing world. However, hospitals and research centres having these possibilities should work further to establish better clinical criteria and simple test methods suited for the actual needs of leprosy control programmes.

\section{Acknowledgments}

We wish to thank Ato Kiros Ayenew for technical assistance. AHRI is financially supported by the Norwegian and Swedish Save the Children Federations. This study was also supported by NIH grant No. 20198 to Wayne State University and AHRI. 


\section{References}

1 Ackerman AB. Histological diagnosis of inflammatory skin diseases. Philadelphia: Lea \& Febiger, 1978; pp 157-67.

2 Antia NH, Mehta, Lata, Vanaja, Irani PF. Clinical, electrophysiological, quantitative histological and ultrastructural studies of the index branch of radial cutaneous nerve in leprosy. Int J Le pr, 1975; 43: 256-64.

3 Antia NH, Pandya NJ. Qualitative histology and quantitative bacteriology in various tissues of 50 leprosy patients. Lepr Rev, 1976; 47: 175-83.

4 Barnetson RS. A prospective study of borderline leprosy reactions. M.D. Thesis, University of Edinburgh, 1977.

5 Browne SG. Leprosy: Clinical aspects of nerve involvement. In: Topics on tropical neurology. Hornabrook RW (ed.), Philadelphia: F. A. Davies Co., 1975; pp 1-16.

${ }^{6}$ Danielsen DC, Boeck CW. Traite de la Spedalsked ou Elephantiasis des des Grecs. Avec un atlas 24 panches colorees. Paris, 1848.

7 Dharmendra. Thickened nerve in diagnosis of leprosy. Lepr India, 1980; 52: 1-2.

8 Nilsen R, Mshana R N, Negesse Y, Mengistu G, Kana B. Immunohistochemical studies of leprous neuritis. Lepr Rev, 1986; 57, suppl 2: 177-87.

9 Ridley DS, Jopling WH. Classification of leprosy according to immunity. A five group system. Int J Lepr, 1966; 34: 255-73.

${ }^{10}$ Ridley DS. Reactions in leprosy. Lepr Rev, 1969; 40: 77-81.

11 Ridley DS. Skin biopsy in leprosy. Basel Documenta Geigy, 1977, pp 37-46.

12 Ridley DS, Ridley MJ. Classification of nerves is modified by the delayed recognition of mycobacterium leprae. Int J Lepr, 1986; 54: 597-606.

13 Srinivasan H, Rao KS, Iyer CGS. Discrepancy in the histopathological features of leprosy lesions in the skin and peripheral nerve. Lepr India, 1982; 54: 275-86.

14 Liu Tze-Chun, Qui Ju-Shi. Pathological findings on peripheral nerves, lymph nodes, and visceral organs of leprosy. Int J Lep, 1984; 52: 377-83. 